\title{
Acoustic mechanisms of a species-based discrimination of the chick-a-dee call in sympatric black-capped (Poecile atricapillus) and mountain chickadees ( $P$. gambeli)
}

\author{
Lauren M. Guillette ${ }^{1}$, Tara M. Farrell ${ }^{1+}$, Marisa Hoeschele ${ }^{1}$ and Christopher B. Sturdy ${ }^{1,2 *}$ \\ Songbird Neuroethology Laboratory/BioCognition Unit, Department of Psychology, University of Alberta, Edmonton, AB, Canada \\ 2 Centre for Neuroscience, University of Alberta, Edmonton, AB, Canada
}

\author{
Edited by: \\ Aaron Blaisdell, University California \\ Los Angeles, USA \\ Reviewed by: \\ Rick Braaten, Colgate University, USA \\ Micheal Dent, University at Buffalo, The \\ State University of New York, USA \\ *Correspondence: \\ Christopher B. Sturdy, Songbird \\ Neuroethology Laboratory/ \\ BioCognition Unit, Department of \\ Psychology, University of Alberta, P217 \\ Biological Sciences Building, \\ Edmonton, AB, Canada T6G 2E9. \\ e-mail:csturdy@ualberta.ca \\ ${ }^{+}$Current address: \\ Tara M. Farrell, Advanced Facility for \\ Avian Research, Department of \\ Psychology, University of Western \\ Ontario, London, ON, Canada.
}

Previous perceptual research with black-capped and mountain chickadees has demonstrated that these species treat each other's namesake chick-a-dee calls as belonging to separate, open-ended categories. Further, the terminal dee portion of the call has been implicated as the most prominent species marker. However, statistical classification using acoustic summary features suggests that all note-types contained within the chick-a-dee call should be sufficient for species classification. The current study seeks to better understand the note-type based mechanisms underlying species-based classification of the chick-a-dee call by black-capped and mountain chickadees. In two, complementary, operant discrimination experiments, both species were trained to discriminate the species of the signaler using either entire chick-a-dee calls, or individual note-types from chick-a-dee calls. In agreement with previous perceptual work we find that the D note had significant stimulus control over species-based discrimination. However, in line with statistical classifications, we find that all note-types carry species information. We discuss reasons why the most easily discriminated note-types are likely candidates to carry species-based cues.

Keywords: black-capped chickadee, chick-a-dee call, mountain chickadee, operant conditioning, songbird vocalization, species discrimination, sympatric

\section{INTRODUCTION}

Bird calls are typically produced year round by both males and females and convey a plethora of information crucial for daily survival. For songbirds, calls function to maintain contact within a pair or flock, raise alarm and mob predators, signal aggression in agonistic encounters, and signal food sources (Marler, 2004). Along with these functional properties, other information may also be encoded in bird calls, such as the individual identity, sex, or species of the caller (e.g., Guillette et al., 2010). The ability to discriminate between species based on vocalizations is advantageous because the signaler (or receiver) may be out of visual range, either due to long distance or obstruction by objects such as foliage. The purpose of the current study is to examine the proximate mechanisms underlying species perception of the chick-a-dee call in two chickadee species that live in sympatry: the black-capped (Poecile atricapillus) and mountain chickadee (P. gambeli).

In the Rocky Mountains of Southwestern Alberta, black-capped and mountain chickadees inhabit the same geographical areas but appear to neither interbreed nor show interspecific territoriality (Hill and Lein, 1989a). In fact, for both species during breeding season, all observed conspecific encounters resulted in aggressive behavior, while less than one-third of interspecific encounters resulted in aggressive behavior (Hill and Lein, 1989b). Because agonistic behavior incurs at the least metabolic costs, avoiding unintentional agonistic encounters through the ability to discriminate conspecific vocalizations from heterospecific vocalizations is advantageous. This is especially true when sympatric species share a call type, such as the chick-a-dee call.
All members of the genus Poecile produce a variant of the acoustically complex chick-a-dee call. The chick-a-dee call of the blackcapped chickadee is composed of four note-types, A, B, C, and D notes (Ficken et al., 1978; Charrier et al., 2004). The chick-a-dee call of the mountain chickadee is composed of four comparable note-types, with the same names, as well as two additional notetypes, $\mathrm{AB}$ and Dhybrid (see Figure 1 for a sound spectrogram of chick-a-dee calls; Bloomfield et al., 2004), although Dhybrid notes are produced, albeit rarely by black-capped chickadee (personal observation). The chick-a-dee call of both species follows a strict production order ( $\mathrm{A} \rightarrow \mathrm{B} \rightarrow \mathrm{C} \rightarrow \mathrm{D}$ in black-capped chickadees and $\mathrm{A} \rightarrow \mathrm{AB} \leftarrow \rightarrow \mathrm{B} \rightarrow \mathrm{C} \rightarrow \mathrm{Dh} \rightarrow \mathrm{D}$ in mountain chickadees); however, any note-type may be repeated or omitted (Ficken et al., 1978; Bloomfield et al., 2004). The functional role of the chick-a-dee call in both species includes raising alarm and coordinating flock movement (Gaddis, 1985; Smith, 1991).

Previous operant GO/NO-GO experiments have shown that blackcapped and mountain chickadees can discriminate between each species' chick-a-dee call and treat the different species' calls as belonging to separate, open-ended categories (Bloomfield et al., 2008a). Other perceptual experiments provide evidence that suggest the terminal dee portion (i.e., $\mathrm{D}$ and $\mathrm{Dh}$ notes) is a more reliable species marker, compared to the initial chick-a portion (i.e., A, AB, B, and C notes) of the chick-a-dee call (Bloomfield et al., 2008b). However, statistical classification by linear discriminant analysis (LDA) of the different note-types, produced by both species, tells a different story (Dawson et al., 2006). Namely, results of the LDA reveal that all note-types are 


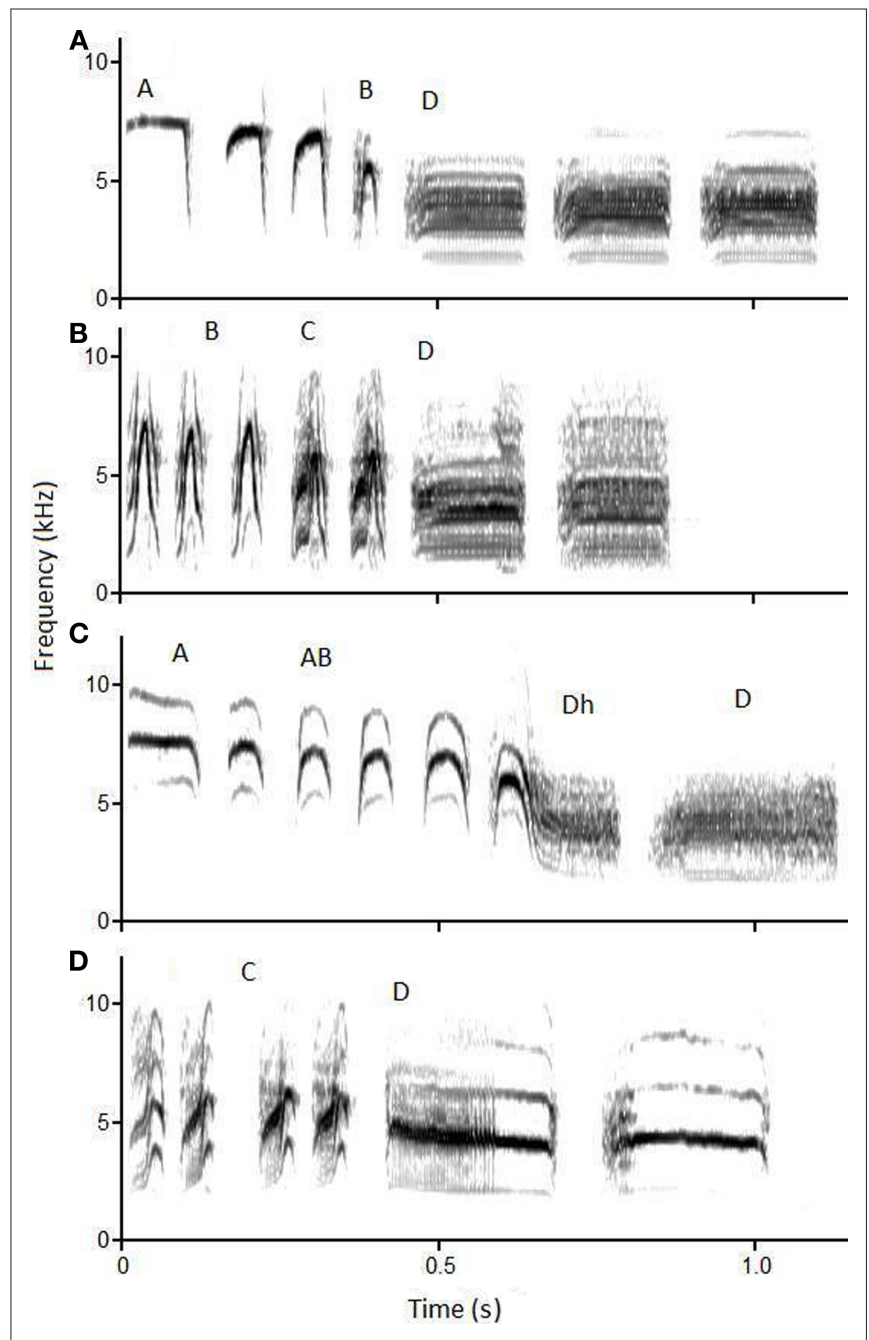

FIGURE 1 | Representative sound spectrograms of frequency ( $\mathrm{kHz}, \boldsymbol{y}$-axis) by time (sec, $\boldsymbol{x}$-axis) of chick-a-dee calls. (A) is produced by a black-capped chickadee, with notes $A, A, A, B, D, D, D$. (B) is produced by a black-capped chickadee, with notes $B, B, B, C, C, D, D$. (C) is produced by a mountain chickadee, with notes $A, A, A B, A B, A B$, Dhybrid, $D$. (D) is produced by a mountain chickadee, with notes $C, C, C, C, D, D$.

sufficiently distinct based on acoustic summary features to accurately classify note-types to each species. In fact, the note-types in the chick- $a$ portion of both species chick-a-dee call resulted in perfect identification of the species of the signaler. When $\mathrm{D}$ notes were classified by the LDA, the accuracy of species identification dropped to $94 \%$. The results of Dawson et al. suggest that species markers may be contained in all note-types that compose the chick-a-dee call, and not just the D note, as previously demonstrated.

The research outlined above has aimed at understanding the acoustic mechanisms of species-based classification of the chick- $a$ dee call in black-capped and mountain chickadees, yet has yielded somewhat conflicting results. In the current study, we attempt to clarify this by conducting two different, species-based, operant discriminations to better understand the note-type mechanisms underlying species classification. In the first discrimination, chickadees were trained with full chick-a-dee calls and then transferred to individual note-types from these calls. The individual note-types were presented either as single exemplars or strings of exemplars to control for temporal differences between the note-types. In the second discrimination, different birds were trained using individual note-types from the chick-a-dee call. Taken together, our results will help to resolve: (1) which note-type(s) control species-based classification, (2) whether the temporal window of note-types affects this ability, and (3) which note-types (between species) are most easily discriminated (i.e., learned the fastest).

\section{EXPERIMENT 1}

In Experiment 1, black-capped and mountain chickadees were trained to discriminate the species of the signaler using natural, full-length chick-a-dee calls as stimuli. After each bird successfully learned this task, it was transferred to individual note-types from the chick-a-dee call. This allows us to see which particular notetype(s), if any, mediate species-based discrimination (i.e., were responded to more).

\section{MATERIALS AND METHODS Subjects}

Eight black-capped chickadees ( $P$. atricapillus; four male, four female) and seven mountain chickadees (P. gambeli; three male, four female) were tested between June 2008 and June 2010. All birds were captured in Kananaskis Country, Alberta, Canada in February 2008, January 2009, or January 2010. Some birds had previous experience in operant conditioning experiments using synthetic tones and black-capped chickadee fee-bee songs. However, all subjects were naive to the current experimental stimuli. The sex of each bird was determined by DNA analysis (Griffiths et al., 1998).

For a minimum of 6 weeks prior to starting the experiment, each bird was housed separately in individual Jupiter Parakeet cages $(30 \mathrm{~cm} \times 40 \mathrm{~cm} \times 40 \mathrm{~cm}$; Rolf C. Hagen Inc., Montreal, Canada), which allowed for visual and auditory, but not physical contact with conspecifics. Black-capped and mountain chickadees were housed in separate colony rooms. Each bird had free access to food (Mazuri Small Bird Maintenance Diet; Mazuri, St. Louis, MO, USA), water (vitamin supplement three times a week; PRIME, Rolf C. Hagen, Inc., Montreal, Canada), grit and cuttle bone. Each bird received one mealworm three times a week, a mixture of eggs and greens twice a week, and three to five sunflower seeds daily. Colony rooms were maintained on a light-dark cycle that mimicked the natural light cycle for Edmonton, Alberta, Canada.

All studies were conducted in accordance with the Canadian Council on Animal Care Guidelines and policies approved by the University of Alberta Biological Sciences Animal Care and Use Committee for Biosciences for the University of Alberta and the Life and Environmental Sciences Animal Care Committee for the University of Calgary. Chickadees were captured under an Environment Canada Canadian Wildlife Service Scientific permit, Alberta Fish and Wildlife Capture and Research permits.

\section{Apparatus}

A detailed description of the experimental operant apparatus is available in Sturdy and Weisman (2006). Briefly, each bird was tested individually, while living in a modified cage $(30 \mathrm{~cm} \times 40 \mathrm{~cm} \times 40 \mathrm{~cm})$. An opening on one end of the cage $(11 \mathrm{~cm} \times 16 \mathrm{~cm})$ gave each bird access to a motor driven feeder (Njegovan et al., 1994). Infrared cells 
were situated on either side of the opening of the feeder, and on a request perch that was located in front of the feeder, to monitor the position of the bird. In addition, each cage contained several perches, water, grit cup, cuttle bone, and a wire mesh floor so that dropped food could not be recovered. A Fostex FE108 $\Sigma$ speaker (Fostex Corp., Japan; frequency range $80-18,000 \mathrm{~Hz}$ ) was located outside of the cage, next to the motor driven feeder, and broadcast acoustic stimuli at $\sim 75-80 \mathrm{~dB}$ as measured by a Radio Shack Sound Level Meter (Radio Shack, Fort Worth, USA). Each cage was housed in a ventilated, sound-attenuating chamber lit by a full spectrum florescent bulb. A single board computer attached to the soundattenuating chamber monitored responses and scheduled trials for each bird. During testing, the light cycle mimicked the natural light-cycle for Edmonton, and each bird received one mealworm twice a day, and eggs and greens twice a week.

\section{Acoustic stimuli}

Forty high-quality, chick-a-dee calls (20 black-capped chickadee, 20 mountain chickadee) were used as acoustic stimuli. Calls were recorded using a variety of microphones and recorders, and were randomly selected from our own database of recordings and several additional sources (i.e., bioacoustic libraries, colleagues, and commercially available compact discs). All calls were bandpass filtered to remove background noise using GoldWave (Version 5.12, GoldWave Inc.). Using SIGNAL (version 4.0, Engineering Design, Berkley, CA, USA), call amplitude was equalized; leading and trailing $5 \mathrm{~ms}$ of silence was added and tapered to remove transients. Each call was saved as an individual sound file. These chick-a-dee calls served as the stimuli for pre-training and discrimination acquisition (ACQ; described below).

Using an additional 84 chick- $a$-dee calls from the same sources as above, individual notes (A, B, C, and D for black-capped chickadees, A, AB, B, C, Dh, and D for mountain chickadees) were edited, modified as the chick-a-dee calls above, and saved as individual files. Using 10 randomly selected exemplars of each note-type, for each species, Single Note and Note String stimuli were created. Single Note stimuli consisted of 10 exemplars (single notes) from each note-type category, for each species. Note Strings were created from Single Note stimuli. See Figure 2 for example spectrograms of Note Strings.

The duration and number of note repetitions in each Note String was based on bioacoustical measurements reported in Charrier et al. (2004) and Bloomfield et al. (2004). Each Note String was created so that it approximated the combined average duration of the chick-a-dee call of black-capped and mountain chickadees. Internote intervals (INIs; the time between notes), were calculated separately for introductory (i.e., A, A/B, B, and C notes) and terminal (i.e., Dh and D notes) portions of the chick-a-dee call. As with the duration of the chick-a-dee calls, the INIs were averaged across both species' introductory and terminal portions (introductory $51.3 \mathrm{~ms}$, terminal: $62.1 \mathrm{~ms}$ ). Therefore, the duration of each Note String exemplar was created by: (1) summing the duration of a specific note exemplar and the INI calculated for the corresponding note-type (i.e., the INI that corresponds to the mean INI for introductory or terminal note-types), (2) determining the number of repetitions of each note exemplar (plus INI) needed to approximate the average length of chick-a-dee calls within one SD

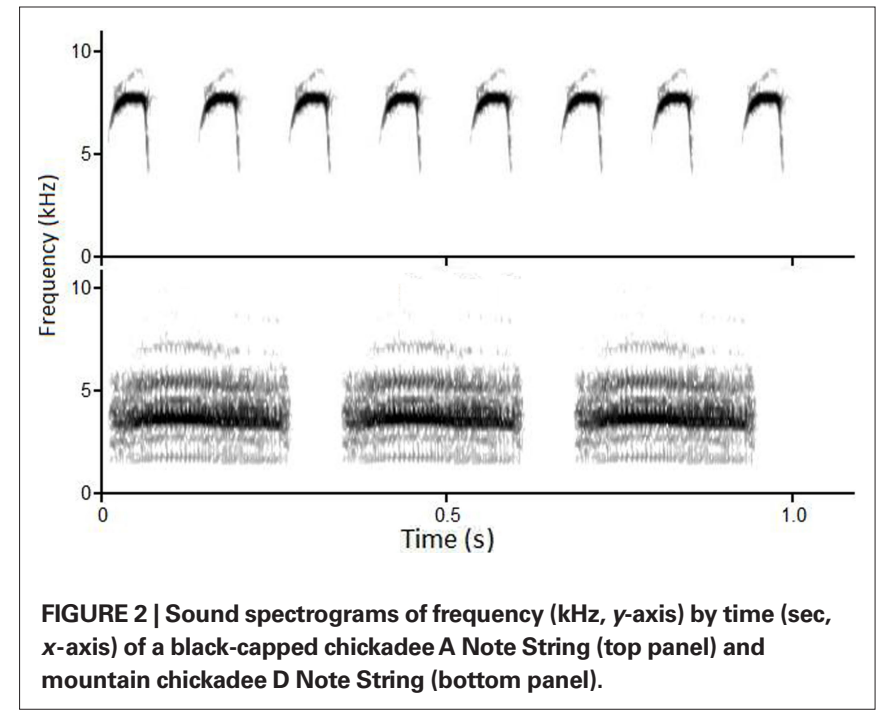

(946.7 $\pm 418.8 \mathrm{~ms})$. The rationale for making the Note Strings equal to an average of both species chick-a-dee calls was to minimize the possibility of species identification by total duration or INI.

\section{PROCEDURE}

\section{Pre-training}

Pre-training began after each bird learned how to request stimuli and eat food from the motor driven feeder. During pre-training, to initiate a trial, a bird had to remain on the request perch (breaking the infrared beam) for a randomly selected interval (range 900-1100 ms). Following this, a chick-a-dee call from a pool of 40 calls (20 each produced by black-capped and mountain chickadees) was randomly selected without replacement and played. If the bird left the request perch before the entire chick-a-dee call finished playing, the trial terminated and a $30 \mathrm{~s}$ inter-trial-interval (ITI) with the house light off commenced. This procedure was to ensure that a bird would remain on the request perch, and listen to the call in its entirety, before flying away, or flying to the feeder. If the bird remained on the request perch for the entire duration of the chick-a-dee call, three different scenarios could ensue (1) bird leaves the request perch within $1 \mathrm{~s}$, but does not fly to the feeder $\rightarrow$ trial ends with no ITI, (2) bird flies to feeder within $1 \mathrm{~s}$ (breaking the infrared beam) $\rightarrow 1 \mathrm{~s}$ access to food followed by a 30 s ITI with the house light on, (3) bird remains on the request perch for longer than $1 \mathrm{~s} \rightarrow 60 \mathrm{~s}$ ITI with house light on that could be terminated by leaving the perch. This last scenario was to ensure that the bird would leave the request perch after a trial ended.

Criterion to complete pre-training was six 500 trial bins with over $60 \%$ responding to all stimuli, and no more than $3 \%$ difference in responding to future $\mathrm{S}+$ and $\mathrm{S}-$ exemplars. This procedure was used to create high, uniform responding to all stimuli that would be used during the training phase of the experiment, while also training each bird to remain on the request perch for the entire duration of a stimulus and to leave the request perch after each stimulus was played.

\section{Species-based discrimination training}

Each bird moved onto discrimination training after it completed pre-training. During discrimination training, visits to the feeder after S+ stimuli were rewarded with $1 \mathrm{~s}$ access to food with a $30 \mathrm{~s}$ 
ITI with the house light on, while visits to the feeder following $\mathrm{S}-$ stimuli resulted in no food access and a $30 \mathrm{~s}$ ITI with the house light extinguished. There were three different phases each bird progressed through during discrimination training: (1) Acquisition (ACQ), (2) Transfer 1 (TR-1), and (3) Transfer 2 (TR-2). In the ACQ phase, each bird discriminated between 2 stimulus sets: 10 foodrewarded $(\mathrm{S}+)$ stimuli of one species category and 10 non-food rewarded (S-) stimuli of the other species category. During TR-1, each bird discriminated 10 novel exemplars from each stimulus set (10 novel S+ and 10 novel S- exemplars). All exemplars used during ACQ and TR-1 were previously heard during pre-training. During TR-2, the stimulus sets from ACQ and TR-1 were pooled so that each bird was discriminating between the $20 \mathrm{~S}+$ and $20 \mathrm{~S}-$ stimuli previously presented. For each phase, each bird was trained until it completed six 500 trial bins with a discrimination ratio (DR, described below in response measures) $\geq 0.80$, with the last two bins occurring consecutively.

Birds were pseudo-randomly (according to species and sex of subject) assigned to one of two discrimination groups: (1) blackcapped chickadee $\mathrm{S}+(\mathrm{BC} \mathrm{S}+)$, or $(2)$ mountain chickadee $\mathrm{S}+(\mathrm{MO}$ $\mathrm{S}+$ ). All birds learned a species (black-capped or mountain chickadee) based discrimination. Birds in both discrimination groups heard the exact same stimuli; however, birds in the BC S+ groups were reinforced for responding to chick-a-dee calls produced by black-capped chickadees, while birds in the MO S+ discrimination group were reinforced for responding to chick-a-dee calls produced by mountain chickadees.

\section{Note-type testing}

After each bird completed discrimination acquisition, it received Single Notes and Note Strings transfer sessions (100\% reinforcement for S+ species category, $0 \%$ reinforcement for S- category) on alternating days with discrimination training (TR-2). Each bird received 4 days of transfer each of Single Notes and Note Strings. The first three bins, where responding was above chance levels, of Single Notes and Note Strings were analyzed. During Note-Type testing, bins consisted of 50 trials each. The order in which each bird was tested (Single Notes or Note Strings first) was randomized across individuals.

\section{RESPONSE MEASURES}

The percent response was calculated for each stimulus exemplar ( $\mathrm{S}+$ and $\mathrm{S}-$ ) by dividing the number of trials on which the bird went to the feeder $(\mathrm{R}+)$ by the total number of trials for that stimulus $(N)$, and then multiplying by 100 . All response percentages were corrected for trials on which the bird left the request perch before the entire stimulus had played $(Z): \mathrm{R}+/(N-Z) \times 100$. To compare responding across individuals for transfer to the Single Notes and Note Strings, percentages of responses were scaled within each subject. Scaling responding within each subject controls for individual differences in the overall level of responding and was calculated by taking the highest percent response for each subject, across all testing notes, and rescaling that to $100 \%$. All other notes were rescaled as a ratio of the highest percent responding. This rescaling was conducted separately for Single Notes and Note Strings. Arcsin transform $\left[2^{\star} \operatorname{Arcsin}(\operatorname{sqrtX})\right] s$ were performed on scaled percent response to correct for any non-normality and allow for parametric statistical testing (repeated measures ANOVAs). The DR was calculated by dividing the average percent response to the $\mathrm{S}+$ stimuli by the average percentage of responses to all ( $\mathrm{S}+$ and $\mathrm{S}-$ stimuli); discrimination is at chance level when the DR is 0.5 and perfect (responding to just $\mathrm{S}+$ stimuli) when the ratio is 1 .

\section{STATISTICAL ANALYSES}

Binomial tests for dichotomous data were calculated to determine whether individuals were responding differently from chance (chance $\mathrm{DR}=0.5$ ) during various points in discrimination ACQ and transfer to Note-Type testing. To test if subjects were responding differently to each note-type during the Note-Type testing, repeated measures ANOVAs were conducted on the arcsin transformed percent responses. Paired $t$-tests were conducted to test for differences in responding between Single Notes and Note Strings. All analyses were conducted in Statistica v8 (Statsoft, Inc.).

\section{RESULTS}

\section{Acquisition of species-based category discrimination}

During the first block of ACQ, 14 of 15 birds responded at chance levels. One bird, a black-capped chickadee in the BC S+group, responded significantly more to $S+\operatorname{stimuli}(Z=2.65, p=0.004)$ by the end of the first 500-trial bin. Each bird responded significantly greater than chance when transferred to novel exemplars of the S+ species category (first bin TR-1: all $Z$ 's $>4.37$, all $p$ 's $<0.001$ ), and when transferred to the combined stimulus set from ACQ and TR-1 (first bin TR-2: all $Z$ 's $>10.75$, all $p$ 's $<0.001$ ). Figure 3 depicts the DRs by species of subject and discrimination group, over various stages.

\section{Note-type testing}

Twelve of the 15 birds continued to respond significantly greater than chance to the $\mathrm{S}+$ species category when they were transferred to the individual note-types from the chick-a-dee calls (first bin NoteType testing: all $Z$ 's $>2.81$, all $p$ 's $<0.002)$. The three individuals that did not respond above chance (all $Z$ 's $<1.96$, all $p$ 's $>0.05$ ) to the $S+$ species category in the first bin of Note-Type testing were all black-capped chickadees in the BC S+ group. Two of these individuals responded above chance by the third bin (150 trials, $Z=2.31$, $p=0.01$ ) and sixth bin (300 trials, $Z=2.12, p=0.02$ ). The third individual never responded above chance to Single Notes, but did respond above chance to Note Strings $(Z=5.04, p<0.001)$. Due to equipment failure, the Single Notes data from one mountain chickadee in the BC S+ group were discarded.

\section{Black-capped chickadee $S+$ discrimination group (BC S+)}

Birds (both black-capped and mountain chickadees) were trained to respond to black-capped chickadee chick-a-dee calls and withhold responding to mountain chickadee chick-a-dee calls. When data from Single Note and Note Strings were combined, birds responded differentially to the four different $S+$ note-types (blackcapped chickadee A, B, C, and D notes; $\left.F_{3,21}=5.98, p=0.004\right)$. A Tukey post hoc test revealed that birds responded significantly more to black-capped chickadee D note $\mathrm{S}+\mathrm{s}$ compared to black-capped chickadee $\mathrm{B}(p=0.004)$ and $\mathrm{C}(p=0.021)$, but not $\mathrm{A}(p=0.181)$ $\mathrm{S}+$ note-types. When responding to the different $\mathrm{S}+$ note-types was compared to responding to the different $\mathrm{S}$ - note-types (mountain 


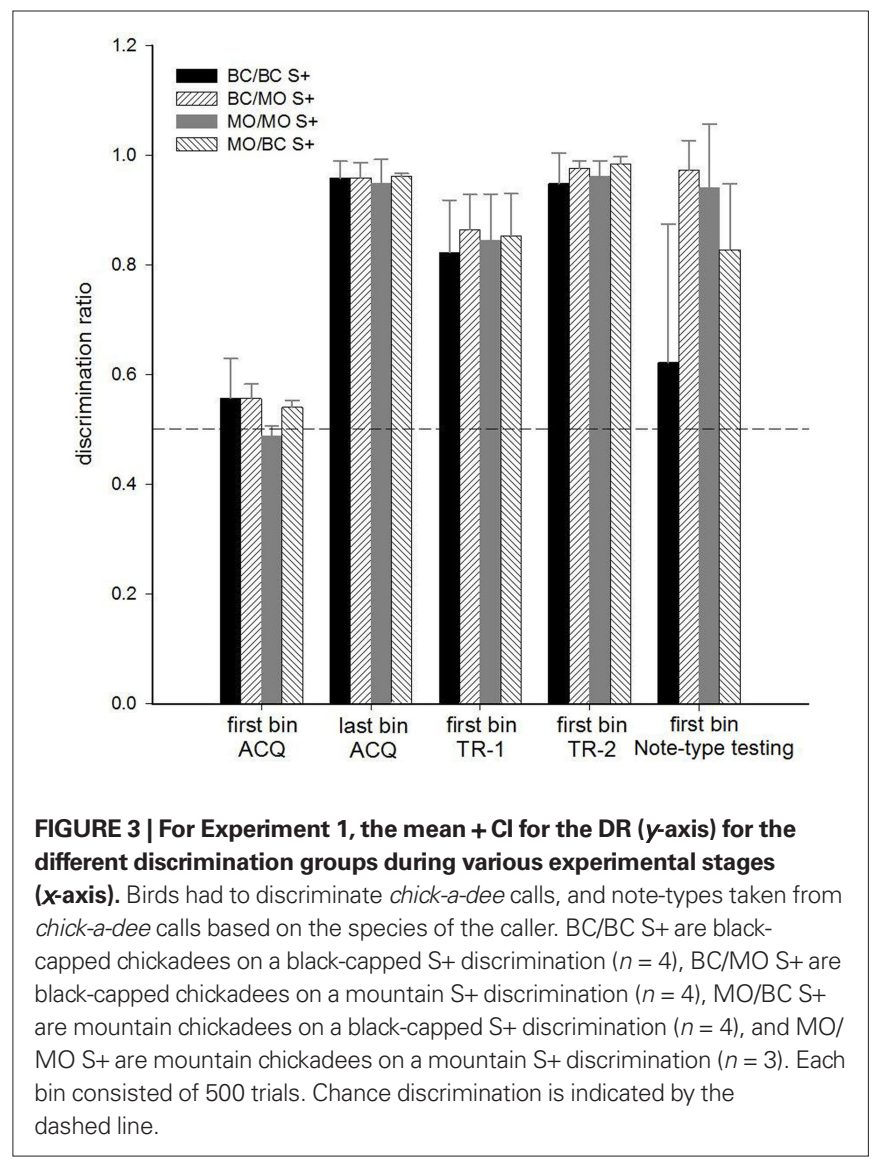

chickadee $\mathrm{A}, \mathrm{AB}, \mathrm{B}, \mathrm{C}, \mathrm{Dh}$, and $\mathrm{D}$ notes) there was a significant effect of note-type, $F_{9,63}=23.89, p<0.001$. A Tukey post hoc test indicated that subjects responded significantly more to A, C, and D notes of the S+ category than to all note-types in the S- category. Birds responded significantly more to B notes in the S+ category than all S- notes-types with the exception of mountain chickadee $\mathrm{A}(p=0.156)$ and $\mathrm{D}(p=0.191) \mathrm{S}-$ note-types. This suggests that the species-based discrimination for black-capped and mountain chickadees on a black-capped chickadee S+ discrimination is likely more easily performed with $\mathrm{D}$ notes, and possibly A notes produced by black-capped chickadees. See Figure 4A, for the mean scaled percent response to each of the S+ and S- note-types.

\section{Mountain chickadee $S+$ discrimination group (MO S+)}

Birds (both black-capped and mountain chickadees) were trained to respond to mountain chickadee chick-a-dee calls and withhold responding to black-capped chickadee chick-a-dee calls. When data from Single Note and Note Strings were combined, birds responded significantly differently to the six different $S+$ note-types (mountain chickadee A, AB, B, C, Dh, and D notes; $F_{5,30}=5.47, p=0.001$ ). A Tukey post hoc test revealed that birds responded significantly more to mountain chickadee $\mathrm{D}$ note $\mathrm{S}+\mathrm{s}$ compared to all other $\mathrm{S}+$ notetypes (mountain chickadee A: $p<0.001 ; \mathrm{AB}: p=0.02 ; \mathrm{B}: p=0.013$; $\mathrm{C}: p=0.003$; and Dh: $p=0.045$ ). When responding to the different $\mathrm{S}+$ note-types was compared to responding to the different $\mathrm{S}$ - notetypes (black-capped chickadee A, B, C, and D notes) there was a significant effect, $F_{9,54}=21.91, p<0.001$. Tukey post hoc analyses revealed that birds responded to all S+ note-types significantly more than all S- note-types (all p's $<0.021$ ). See Figure $4 B$ for the mean scaled percent response to each of the S+ and S- note-types.

\section{Differential responses to Single Note versus Note Strings}

Because Note Strings allowed birds a longer temporal window to potentially identify the species of the caller, paired $t$-tests were performed to assess differences in responding between Single Note and Note Strings pairs in the S+ species category. Birds in the BC S+ discrimination group responded significantly more to the $\mathrm{C}$ Note $\mathrm{Strings}$ compared to the C Single Notes, $t_{5}=-2.76, p=0.04$. There was no difference in responding between Single note and Note Strings for the remaining three note-types (A notes: $t_{5}=-0.99, p=0.365$; B notes: $t_{5}=-0.44, p=0.676$; D notes: $\left.t_{5}=-0.68, p=0.532\right)$. Birds in the $\mathrm{MO}$ $S+$ discrimination group responded significantly more to $A B$ Note Strings compared to AB Single Notes, $t_{6}=-3.27, p=0.02$. There was no difference in responding between Single Note and Note Strings for the remaining five note-types (A notes: $t_{6}=-1.59, p=0.16$; B notes: $t_{6}=-2.39, p=0.054 ;$ C notes: $t_{6}=-2.09, p=0.08 ; \mathrm{Dh}: t_{6}=0.87$, $p=0.02$ D notes: $t_{6}=1.71, p=0.42$ ). This suggested that the extended temporal window afforded to birds in the Note Strings transfer did not aid the birds in a species-based discrimination compared to hearing a single presentation of a note (Single Note) except for black-capped chickadee $\mathrm{C}$ notes and mountain chickadee $\mathrm{AB}$ notes.

\section{EXPERIMENT 2}

In this experiment, a new group of black-capped and mountain chickadees was also trained on a species-based discrimination, as in Experiment 1. However, unlike in Experiment 1, where the training stimuli were entire, full-length chick-a-dee calls, here, birds were trained to discriminate the species of the signaler using individual note-types from the chick-a-dee call. This allows us to determine which note-types were most easily discriminated, and thus would maximally support species-based discrimination and classification.

\section{MATERIALS AND METHODS Subjects}

Eight black-capped chickadees (four male, four female) and eight mountain chickadees (four male, four female) were tested between June 2008 and June 2010. All birds were captured in Kananaskis Country, Alberta, Canada in February 2008, January 2009, or January 2010. Some birds had previous experience in operant conditioning experiments using synthetic tones and fee-bee songs of the black-capped chickadee. However, all subjects were naive to the current experimental stimuli and were different birds from those used in Experiment 1. The colony room conditions and testing apparatus remained as in Experiment 1.

\section{Acoustic stimuli}

The acoustic stimuli for Experiment 2 were single notes obtained from chick-a-dee calls of black-capped and mountain chickadees from the same sources as in Experiment 1. All acoustic stimuli in the current experiment were processed in the same manner to Experiment 1. The stimuli consisted of 80 exemplars total: 10 exemplars each of black-capped chickadee A, B, C, and D notes, and mountain chickadee A, B, C, and D notes. 

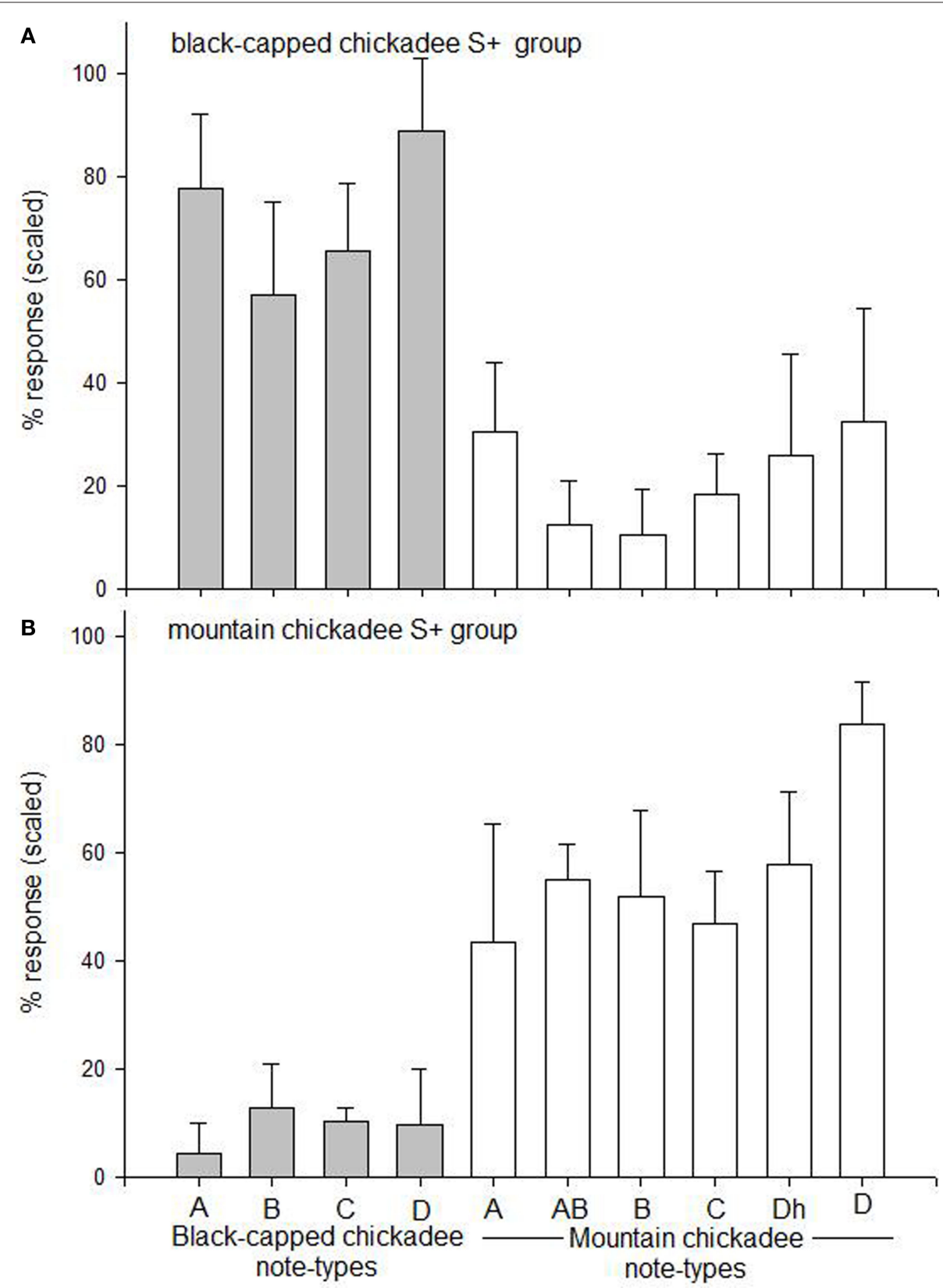

FIGURE 4 | For Experiment 1, the mean scaled percent response + Cl ( $y$-axis) for each of the black-capped chickadee and mountain chickadee note-types ( $\boldsymbol{x}$-axis). (A) Represents both black-capped $(n=4)$ and mountain chickadees $(n=4)$ that were trained to respond to full chick-a-dee calls produced by black-capped chickadees, and withold responding to full chick-a-dee call produced by mountain chickadees. (B) Represents both black-capped chickadees $(n=4)$ and mountain chickadees $(n=3)$ that were trained to respond to full chick-a-dee calls produced by mountain chickadees and withold responsing to chick-a-dee calls produced by black-capped chickadees. The data presented is from combined Single Note and Note Strings. Responses were scaled to control for individual differences in overall rate of responding.

\section{PROCEDURE}

\section{Pre-training}

Each bird was rewarded for responding (going to the feeder) to all 80 note exemplars (10 each of black-capped chickadee A, B, C, and D notes, and mountain chickadee A, B, C, and D notes). All other rules and criterion for pre-training from Experiment 1 were the same in Experiment 2.

\section{Species-based discrimination acquisition}

As in Experiment 1, birds were trained on a species-based discrimination, however in the current experiment there was only one phase, discrimination acquisition (ACQ). During ACQ each bird discriminated between $20 \mathrm{~S}+$ stimuli (five exemplars of each note-type from one species) and $20 \mathrm{~S}$ - stimuli (five exemplars of each note-type from the other species). Each bird was 
trained until it performed six 500 trial bins with a $\mathrm{DR} \geq 0.80$, with the last two bins occurring consecutively. For each bin, we calculated a separate DR for each note-type category (i.e., A, B, C, and D).

Birds were pseudo-randomly (according to species and sex of subject) assigned to one of two discrimination groups: (1) blackcapped chickadee S+ (BC S+), or (2) mountain chickadee S+ (MO $\mathrm{S}+$ ). All birds were trained on a species-based (black-capped or mountain chickadee) discrimination. Birds in both discrimination groups heard the exact same stimuli; however, birds in the $\mathrm{BC}$ S+ group were reinforced for responding to individual notes from black-capped chickadee chick-a-dee calls, while birds in the MO S+ discrimination group were reinforced for responding to individual notes from mountain chickadee chick-a-dee calls. In sum, in each discrimination group there were four black-capped chickadees (two male, two female) and four mountain chickadees (two male, two female).

\section{RESPONSE MEASURES}

The percent response was calculated as in Experiment 1. In the current experiment we calculated a DR for each note-type pair, resulting in four distinct DRs for each 500-trial bin of data (e.g., DR for A notes, DR for B notes, etc.). The DR was calculated by dividing the average percent response to the $\mathrm{S}+$ stimuli by the average percentage of responses to all ( $\mathrm{S}+$ and $\mathrm{S}-$ ) stimuli within each note-type category. Discrimination performance is at chance when the DR is 0.5 and perfect (responding to just $\mathrm{S}+$ stimuli) when the ratio is 1 . The note-type order in which each bird learned the species-based classification was ranked, from 1 (i.e., learned in the fewest trials) to 4 (i.e., learned in the most trials). Each bird was exposed to, and could potentially learn to discriminate between all four note-types simultaneously; hence, ranks were not mutually exclusive. In the cases where a bird reached criteria for two note-types in the same number of bins, a tie rank was awarded. For instance if both $\mathrm{A}$ and $B$ note criteria were reached in the same amount of bins, before $C$ and $\mathrm{D}$ notes criteria were reached, $\mathrm{A}$ and $\mathrm{B}$ notes would receive $\mathrm{a}$ rank score of 1.5. There were six total instances of ties, resulting in 12 tie rank scores out of 64 total scores.

\section{STATISTICAL ANALYSIS}

Kruskal-Wallis one-way ANOVAs by ranks were conducted. If the probability of the obtained $H$ is less than $5 \%$, then all six possible pairwise comparisons were performed. These comparisons were adjusted to control for familywise Type I error (Siegel and Castellan, 1988), all statistics were run in PASW v18.

\section{RESULTS}

When the data were collapsed across species of the subject, birds learned the species discrimination at different rates (i.e., in fewer trials) for some note-types than others, $H(3, N=64)=29.19$, $p<0.001$. D notes were learned in fewer trials than B notes $(p<0.001)$ or $\mathrm{C}$ notes $(p<0.001)$. Analysis of species separately revealed that black-capped chickadees learned $\mathrm{D}$ notes in fewer trials than any other note-type $[H(3, N=32)=15.49, p=0.001$; A notes: $p=0.03$, B notes: $p=0.01$, C notes: $p=0.002$ ], while mountain chickadees learned D notes in fewer trials than B or C notes $[H(3, N=32)=16.54, p=0.001$; B notes: $p=0.04$, C notes: $p=0.002]$, and learned A notes in fewer trials than C notes $(p=.02)$. The results of these Kruskal-Wallis tests are presented in Table 1. In sum, the species-based discrimination was solved fastest by $\mathrm{D}$ notes and, to a lesser degree, A notes. See Figure 5 for bar graphs depicting the mean rank order learned.

\section{DISCUSSION}

In the two experiments reported here, we trained sympatric blackcapped and mountain chickadees on species-based discriminations of the chick-a-dee call. In the first experiment, birds were trained to discriminate the species of the signaler using natural, full-length chick-a-dee calls as stimuli, and then transferred to individual notetypes from these calls to determine which note-types, if any, mediated species-based discrimination. In the second experiment, a new group of sympatric black-capped and mountain chickadees was also trained on a species-based discrimination. However, unlike the first experiment where the training stimuli were entire, full-length calls, here, birds were trained to discriminate the species of the signaler using individual note-types from the chick-a-dee call, to determine which note-types were most easily discriminated, and thus would maximally support species-based discrimination and classification.

The current experiments extend previous work conducted with black-capped and mountain chickadees on species-based discriminations and LDA that classified note-types according to the species of the signaler (Dawson et al., 2006; Bloomfield et al., 2008a,b). Bloomfield et al. (2008b) found that the dee portion (i.e., D notes) of the chick-a-dee call contained more species-specific information (was easier to discriminate) compared to the chick-a portion (i.e., A, $\mathrm{B}$, and C notes). However, correct classification of the species of the signaler by LDA suggested that all note-types from the chick-a-dee call should be sufficient for species identification (Dawson et al., 2006). In both of the current experiments we find that D notes may carry more species-based information, and this finding is not likely due simply to the longer duration of $\mathrm{D}$ notes compared to other

Table 1 | For Experiment 2, the results of the Kruskal-Wallis one-way ANOVA by ranks for different groups of birds.

\begin{tabular}{|c|c|c|c|c|c|c|c|c|}
\hline Group & \multicolumn{2}{|c|}{ Omnibus } & \multicolumn{6}{|c|}{ Pairwise comparisons $p^{\prime}$ s } \\
\hline BC only & 15.492 & $0.001 *$ & $0.030^{*}$ & $0.014^{*}$ & $0.002^{*}$ & 1.000 & 1.000 & 1.000 \\
\hline MO only & 16.541 & $0.001 *$ & 1.000 & $0.044^{*}$ & $0.003^{*}$ & 0.207 & $0.022 *$ & 1.000 \\
\hline
\end{tabular}

All significant differences are starred. 


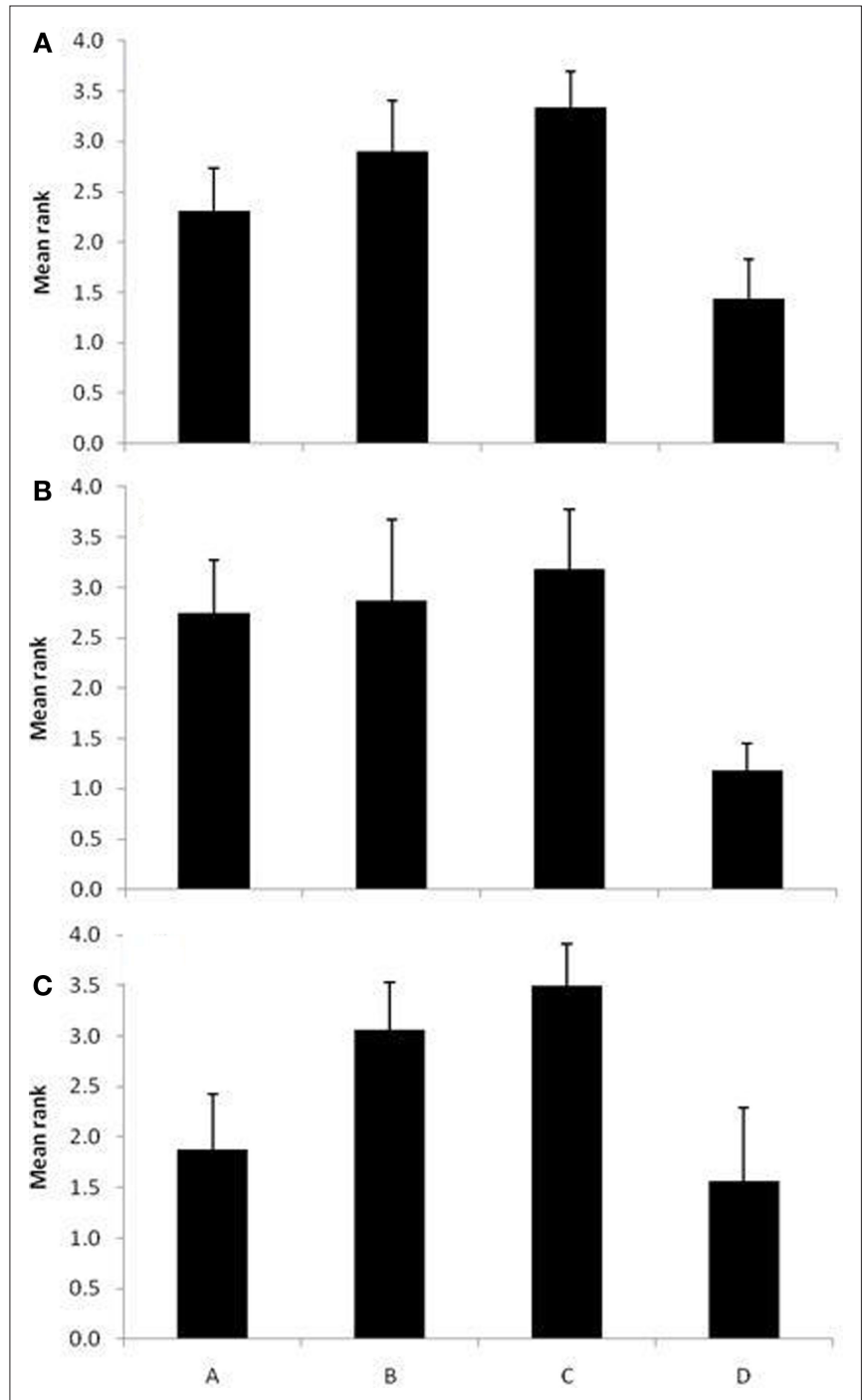

FIGURE 5 | For Experiment 2, the mean rank order $+\mathrm{Cl}$ ( $y$-axis) of note-types in which the species-based classification was learned. The note-types are listed on the $x$-axis. (A) All birds $(n=16)$, (B) black-capped chickadees $(n=8)$, and (C) mountain chickadees $(n=8)$.

note-types. We also found some evidence suggesting that A notes carry species markers more so than B or C notes. Nonetheless, in line with the results of the LDA (Dawson et al., 2006), we find that all notes-types carry some species-specific information, but not to the extent of the D note, and possibly the A note.

In the first experiment, most birds were able to discern the species of the caller using individual note-types from the chick-a-dee call after being trained with full calls. Three black-capped chickadees did not perform above chance when initially transferred (i.e., within the first 50 trials) to the individual note-types when the food-rewarded category was conspecific vocalizations. Two of these individuals were responding above chance within 300 trials (i.e., six-50 trial bins). However, one individual never responded above chance to single note presentations, even after extensive training. This suggests that there might have been too large of a temporal discrepancy between full call training stimuli and single note stimuli for this individual to overcome. Interestingly, the individual that failed to learn the species-based discrimination using single notes presentations was able to discriminate species of the signaler when strings of a single note-type were used. Perhaps this particular individual was able to solve this discrimination because the strings of notes were the same length as average chick-a-dee calls, which is the length that all birds were initially trained on.

Of all the note-types, the D note was responded to the most, and therefore likely conveys the most species information in both blackcapped and mountain chickadee chick-a-dee calls. This idea is further supported by the results of the second experiment. Birds learned to discriminate between $\mathrm{D}$ notes in fewer trials than either $\mathrm{B}$ or $\mathrm{C}$ notes. Based on the total duration of note-types, the $\mathrm{D}$ notes appear to be a good candidate for species identification because they are substantially longer than most other note-types (with the exception of Dh notes) and this longer temporal window may allow the receiver more time to process the species of the signaler. While this seems like a plausible hypothesis, evidence from the current study suggests that the contribution of the D note to effectively communicating the species of the signaler is more than just its temporal advantage. With the exception of one note-type of each species (black-capped chickadee $\mathrm{C}$ and mountain $\mathrm{AB}$ note) birds did not respond differentially when presented with a single note exemplar, which are on the order of $<100 \mathrm{~ms}$, compared to a string of notes with the same temporal window as an average chick-a-dee call ( $946.7 \pm 418.8 \mathrm{~ms})$. Repeating a note for several iterations should have allowed birds more time to perceive subtle cues that may guide species discrimination. While our procedure does not control for the note length of a single note, and $\mathrm{D}$ notes may have more species-specific cues embedded within the signal, it still controls for the duration of note exposure.

The stronger response of birds in the $\mathrm{BC}$ S+ group to strings of $\mathrm{C}$ notes, compared to a single $\mathrm{C}$ note is perhaps influenced by the functional relevance of the $\mathrm{C}$ note. In a study with Carolina chickadees (P. carolinensis), Freeberg and Lucas found that chickadees took seed from a novel food stand more often when a playback was broadcast that contained chick-a-dee calls that were rich in C notes, compared to chick-a-dee calls that were rich in D notes (2002). The birds also differed in their vocal response to these two call types $(\mathrm{C}$ note rich versus $\mathrm{D}$ note rich), producing more chick-a-dee calls during the playback of calls that had contained many C notes. Although this study did not directly examine the effect of chick-a-dee calls containing few $\mathrm{C}$ notes, it does suggest that calls containing many $\mathrm{C}$ notes are related to food. However, in another study with Carolina chickadees, chick-a-dee calls with a large number of D notes were shown to recruit more birds to a feeder, compared to chick-a-dee calls with fewer D notes, likewise, the first bird at a food source produced chick-a-dee calls with significantly more D notes compared to chick-a-dee calls produced by the second bird that arrived at the feeder (Mahurin and Freeberg, 2009). The results of the first of these field studies with Carolina chickadees, combined with the results obtained here, suggest a possible interaction between strings of $\mathrm{C}$ notes used as $\mathrm{S}+$ stimuli and discrimination behavior in an appetitive operant conditioning task.

We have shown that D notes, and to a lesser extent that A notes, were responded to most (Experiment 1) and were most easily discriminated (Experiment 2), in species-based classifications 
between black-capped and mountain chickadees. Next we discuss and suggest reasons why the D and the A notes are likely candidates to carry species-based cues based on previous work. We start with the D note. Because the D note is lower in frequency compared to the introductory A, B, and C notes, it has been suggested that it may function in long-range communication such as flock identification (Mammen and Nowicki, 1981), recruitment to food (Mahurin and Freeberg, 2009), and predator mobbing (Templeton et al., 2005). In fact, D notes of black-capped chickadees have been shown to propagate with a higher signal to noise ratio, at distances of up to $100 \mathrm{~m}$, compared $\mathrm{A}$ or B notes, but not $\mathrm{C}$ notes, in the mixed forest types in which chickadees usually reside (Proppe et al., 2010). In sum, previous research shows that D notes propagate further in the mixed forest where chickadee live and are used in long-range communication and serve a variety of functional roles. The results of the current experiment demonstrate that D notes likely include conspicuous cues that can be used in species identification.

While there is evidence to suggest a plethora of functional roles for the D note (e.g., Mammen and Nowicki, 1981; Templeton et al., 2005) and C note (e.g., Freeberg and Lucas, 2002), the same cannot be said of the A note. The A note does not propagate far in mixed forests compared to the D note; therefore the A note is likely used in closer-range communication (Proppe et al., 2010). However, black-capped and mountain chickadees are often found feeding in mixed species groups during winter months (Smith, 1991; personal observation). Although birds are within close range of each other, they may be visually obscured by foliage and therefore, having a close-range communicative component that contains species identity cues could prove advantageous. Therefore it is likely that that close-range communication components (A note), in addition to long-range communication components ( $D$ note) in the chick-a-dee call of black-capped and mountain chickadees contain species-specific cues.

There are two non-mutually exclusive ideas that explain why the A note might carry species-specific information: the seeming innateness of the A note (Hughes et al., 1998) and the inflexible

\section{REFERENCES}

Bloomfield, L. L., Charrier, I., and Sturdy, C. B. (2004). Note types and coding in Parid vocalizations II: the chick-adee call of the mountain chickadee (Poecile gambeli). Can. J. Zool. 82, 780-793.

Bloomfield, L. L., Farrell, T. M., and Sturdy, C. B. (2008a). Open-ended categorization of "chick-a-dee" calls by sympatric and allopatric chickadees. Behav. Processes 77, 73-86.

Bloomfield, L. L., Farrell, T. M., and Sturdy, C. B. (2008b). All "chick-adee" calls are not created equally Part II. Mechanisms for discrimination by sympatric and allopatric chickadees. Behav. Processes 77, 87-99.

Charrier, I., Bloomfield, L. L., and Sturdy, C. B. (2004). Note types and coding in Parid vocalizations I: the chick-a-dee call of the black-capped chickadee

production order of note-types in the chick-a-dee call (Ficken et al., 1978). In addition to being innate, the A note is included in $59 \%$ of mountain chickadee and $93 \%$ of black-capped chickadee chick- $a$ dee call and when the A notes is included, it always appears as the first note-type. In another species of songbird, the white-crowned sparrow, the first syllable of song remains constant across the species, and serves as a species-specific cue (Soha and Marler, 2000). Because production of the A note is innate, produced often and first in the chick-a-dee call, it might be a good candidate for carrying species identity for short-range communication.

The current experiments demonstrate that the $\mathrm{D}$ notes from the chick-a-dee call of sympatric black-capped and mountain chickadees may contain more species-based information compared to other note-types and that D notes were learned first in a speciesbased discrimination. However, B, C, and especially A notes also contain at least some species-specific cues. The next step to further elucidate the mechanisms of species-based classification in chickadees will be to test sympatric and allopatric non-Paridae songbirds on the discriminations used in the current experiment.

\section{ACKNOWLEDGMENTS}

We thank Isaac Lank and Lou Omerzu for outstanding and timely fabrication and technical assistance, Dawson Clary, Craig Anderson, Shannon Wowk, Jon Gaspar, Justin Duval, and Ashley McKillop for aid in running instrumental training. This research was supported by a Natural Sciences and Engineering Research Council of Canada (NSERC) Discovery Grant, an Alberta Ingenuity Fund (AIF) New Faculty Grant, a Canada Foundation for Innovation (CFI) Infrastructure Operating Fund, a CFI New Opportunities Grant along with start-up funding and CFI partner funding from the University of Alberta, Edmonton, Alberta, Canada to Christopher B. Sturdy. Lauren M. Guillette is supported by an Izaak Walton Killam Memorial Scholarship at the University of Alberta. Tara M. Farrell was supported by an NSERC Undergraduate Summer Research Award. Marisa Hoeschele is supported by an NSERC Post Graduate Scholarship-Doctoral and an Alberta Ingenuity Graduate Student Scholarship.

(Poecile atricapillus). Can. J. Zool. 82, 769-779.

Dawson, M. R. W., Bloomfield, L. L., Charrier, I., and Sturdy, C. B. (2006). Statistical classification of the blackcapped (Poecileatricapillus) and mountain chickadee (Poecile gambeli) call notes. J. Comp. Psychol. 120, 147-153.

Ficken, M. S., Ficken, R. W., and Witkin, S. R. (1978). Vocal repertoire of the black-capped chickadee. Auk 95, 34-48.

Freeberg, T. M., and Lucas, J. R. (2002). Receivers respond differently to chick-a-dee calls varying in note composition in Carolina chickadees, Poecile carolinensis. Anim. Behav. 63, 837-845.

Gaddis, P. K. (1985). Structure and variability in the vocal repertoire of the mountain chickadee. Wilson Bull. 97, 30-46.
Griffiths, R., Double, M. C., Orr, K., and Dawson, R. J. G. (1998). A DNA test to sex most birds. Mol. Ecol. 7, 1071-1075.

Guillette, L. M., Bloomfield, L. L., Batty, E. R., Dawson, M. W. R., and Sturdy, C. B. (2010). Black-capped (Poecile atricapillus) and mountain (Poecile gambeli) contact calls contain species, sex, and individual identity features. J. Acoust. Soc. Am. 127, 1116-1123.

Hill, B. G., and Lein, M. R. (1989a). Territory overlap and habitat use of sympatric chickadees. Auk 106, 259-268.

Hill, B. G., and Lein, M. R. (1989b). Natural and simulated encounters between sympatric black-capped and mountain chickadees. Auk 106, 645-652.

Hughes, M., Nowicki, S., and Lohr, B. (1998). Call learning in black-capped chickadees (Parus atricapillus): the role of experience in the development of "chick-a-dee" calls. Ethology 104, 232-249.

Mahurin, E. J., and Freeberg, T.M. (2009). Chick-a-dee call variation in Carolina chickadees and recruiting flockmates to food. Behav. Ecol. 20, 111-116.

Mammen, D. L., and Nowicki, S. (1981). Individual differences and withinflock convergence in chickadee calls. Behav. Ecol. Sociobiol. 9, 179-186.

Marler, P. (2004). "Bird calls: a cornucopia for communication," in Nature's Music, eds P. Marler and H. Slabbekorn (San Diego, CA: Elsevier), 132-176.

Njegovan, M., Hilhorst, B., Ferguson, S., and Weisman, R. (1994). A motor driven feeder for operant training in songbirds. Behav. Res. Methods Instrum. Comput. 26, 26-27. 
Proppe, D. S., Bloomfield, L. L., and Sturdy, C. B. (2010). Acoustic transmission of the chick-a-dee call of the black capped chickadee (Poecile atricapillus): forest structure and note function. Can. J. Zool. 88, 788-794.

Siegel, S., and Castellan, N. (1988). Nonparametric Statistics for the Behavioral Sciences, 2nd Edn. New York: McGraw-Hill, Inc.

Smith, S. M. (1991). The Black-Capped Chickadee: Behavioral Ecology and Natural History. Ithaca, NY: Cornell University Press.
Soha, J. A., and Marler, P. (2000). A species-specific acoustic cue for selective song learning in the whitecrowned sparrow. Anim. Behav. 60, 297-306.

Sturdy, C. B., and Weisman, R. G. (2006). Rationale and methodology for testing auditory cognition in songbirds. Behav. Processes 72 , 265-272.

Templeton, C. N., Greene, E., and Davis, K. (2005). Allometry of alarm calls: black-capped chickadees encode information about predator size. Nature 308, 1934-1937.
Conflict of Interest Statement: The authors declare that the research was conducted in the absence of any commercial or financial relationships that could be construed as a potential conflict of interest.

Received: 22 October 2010; Paper pending published: 10 November 2010; accepted: 01 December 2010; published online: 14 December 2010.

Citation: Guillette LM, Farrell TM, Hoeschele M, and Sturdy CB (2010) Acoustic mechanisms of a species-based discrimination of the chick-a-dee call in sympatric black-capped (Poecile atricapillus) and mountain chickadees (P. gambeli). Front. Psychology 1:229. doi: 10.3389/ fpsyg.2010.00229

This article was submitted to Frontiers in Comparative Psychology, a specialty of Frontiers in Psychology.

Copyright @ 92010 Guillette, Farrell, Hoeschele and Sturdy. This is an openaccess article subject to an exclusive license agreement between the authors and the Frontiers Research Foundation, which permits unrestricted use, distribution, and reproduction in any medium, provided the original authors and source are credited. 